\section{Myrothenones A and B, Cyclopentenone Derivatives with Tyrosinase Inhibitory Activity from the Marine-Derived Fungus Myrothecium sp.}

Xifeng LI, ${ }^{a}$ Min Kyung KIM, ${ }^{a}$ Uk LeE, ${ }^{a}$ Se-Kwon KIM, ${ }^{a}$ Jung Sook KanG, ${ }^{b}$ Hong Dae CHOI, ${ }^{c}$ and Byeng Wha SoN ${ }^{*}, a$

${ }^{a}$ Department of Chemistry, Pukyong National University; Busan 608-737, Korea: ${ }^{b}$ College of Dentistry, Pusan National University; Busan 602-739, Korea: and ${ }^{c}$ Department of Chemistry, Dongeui University; Busan 614-714, Korea.

Received January 7, 2005; accepted February 2, 2005

New 3-amino-5-ethenylcyclopentenones, myrothenones A (4) and $B(5)$, were isolated together with known 6-n-pentyl- $\alpha$-pyrone (1), trichodenone $A$ (2), and cyclonerodiol (3) from the marine algicolous fungus of genus of Myrothecium. The structure and absolute stereochemistry of the new compounds were established by spectral interpretation and $\mathrm{X}$-ray analysis. Compounds 1 and 4 exhibited a tyrosinase inhibitory activity with $\mathrm{IC}_{50}$ value of 0.8 and $6.6 \mu \mathrm{M}$, respectively, which are more active than kojic acid $\left(\mathrm{IC}_{50}, 7.7 \mu \mathrm{M}\right)$ currently being used as a functional personal-care compound.

Key words marine-derived fungus; Myrothecium sp.; myrothenone; 6- $n$ pentyl- $\alpha$-pyrone; trichodenone $\mathrm{A}$; tyrosinase inhibitory activity

Marine microorganisms such as bacteria and fungi inhabit virtually any environment in the sea, and they are the source of greatest diversity in the sea. ${ }^{1,2)}$ The source of increasing interests, these microbes have been shown to produce novel substances with utilities in fine chemicals, drugs and cosmetics, and functional personal-care products. ${ }^{3)}$

Tyrosinase is known as a key enzyme implicated in the metabolism of melanin in melanocytes, and it is involved in skin-coloring and local hyperpigmentation such as melasma, ephelis, and lentigo. ${ }^{4}$

Therefore, the anti-tyrosinase active compounds have been of great concern as functional personal-care products for skin-whitening effects and for preventive and therapeutic effects on the local hyperpigmentation diseases.

In our screening aimed at identifying tyrosinase inhibitors of microbial origin, we investigated tyrosinase inhibiting activity from the fungal extracts, and a significant activity was observed in three strains (MFA58, 581 and 898). The anti-tyrosinase active component of two strains (MFA581 and 898) was purified by assay-guided isolation to yield the known kojic acid. ${ }^{5,6)}$

In a continuing study on the anti-tyrosinase active fungal strain (MFA58), we found 6- $n$-pentyl- $\alpha$-pyrone $(\mathbf{1}),{ }^{7)}$ trichodenone A (2), ${ }^{8}$ cyclonerodiol (3), ${ }^{9}$ and cyclopentenones designated as myrothenones A (4) and B (5) produced by the marine-derived fungus Myrothecium sp. In this paper, the structure determination of $\mathbf{4}$ and $\mathbf{5}$ and tyrosinase inhibitory activity of $\mathbf{1}$ and $\mathbf{4}$ are reported.

The fungal strain (stock \#, MFA58) was isolated from the surface of the marine green alga Enteromorpha compressa collected at Baegunpo, Busan in 2002. The fungus, identified to be an Myrothecium sp. by fatty acid methyl ester analy-

sis, ${ }^{10)}$ was cultured $(101)$ in a seawater-based medium. ${ }^{11)}$ The filtered broth was extracted with EtOAc to afford crude extracts $(0.8 \mathrm{~g})$. The extract revealed a significant anti-tyrosinase activity, and it was separated by assay-guided fractionation using repeated silica gel flash chromatography ( $n$-hexane in ethyl acetate) and HPLC (ODS-A, $\mathrm{MeOH}-\mathrm{H}_{2} \mathrm{O}=5: 1$ ) to yield compounds $\mathbf{1}(150 \mathrm{mg}), \mathbf{2}(3.5 \mathrm{mg}), 3(17.0 \mathrm{mg}), 4$ (8.0 $\mathrm{mg})$, and $\mathbf{5}(8.5 \mathrm{mg})$.

Myrothenone B (5) ${ }^{12)}$ was isolated as a colorless oil, which was analyzed for $\mathrm{C}_{7} \mathrm{H}_{9} \mathrm{NO}_{2}$ (4 unsaturations) by HR-FAB-MS and ${ }^{13} \mathrm{C}$-NMR methods. The IR absorption spectrum of $\mathbf{5}$ showed bands characteristic of a hydroxyl and amino groups $\left(3390 \mathrm{~cm}^{-1}\right)$ and enone $\left(1630 \mathrm{~cm}^{-1}\right)$ functionality.

The ${ }^{1} \mathrm{H}$ - and ${ }^{13} \mathrm{C}$-NMR spectra, including distortionless enhancement by polarization transfer (DEPT), showed one monosubstituted double bond, one trisubstituted double bond, one primary amine, one oxygenated quaternary carbon, one carbonyl carbon, and one diastereotopic methylene.

The overall NMR data indicated the presence of a trisubstituted enone, a 3-hydroxy-3,4-dialkyl-1-butene, and an amino group. The presence of a 3-aminoenone chromophore was further supported by UV spectral data $[203 \mathrm{~nm}(\log \varepsilon$ 3.7), $268 \mathrm{~nm}(\log \varepsilon 4.0)]$ and by the characteristic double bond carbon signals $[\delta 95.8(\mathrm{~d}), \mathrm{C}-2 ; 174.7$ (s), C-3] located considerably upfield and downfield, respectively. ${ }^{13)}$

The connection of functional groups in $\mathbf{5}$ was achieved on the basis of 2D NMR, ${ }^{1} \mathrm{H}$-detected heteronuclear multiplequantum coherence (HMQC) and heteronuclear multplebond coherence (HMBC), which allowed all carbons and their respective protons to be assigned. Diagnostic HMBC from $\mathrm{H}-2$ to $\mathrm{C}-4$ and $\mathrm{C}-5$, and from $\mathrm{H}_{2}-4$ to $\mathrm{C}-1, \mathrm{C}-2$, and C6, from $\mathrm{H}-6$ to $\mathrm{C}-1, \mathrm{C}-4$, and $\mathrm{C}-5$, and from $\mathrm{H}_{2}-7$ to $\mathrm{C}-5$ and $\mathrm{C}-6$ showed the connections of $\mathrm{C} 1-\mathrm{C} 5$ and $\mathrm{C} 3-\mathrm{C} 4$ in 5 . On the basis of all the foregoing evidence, the structure of myrothenone $\mathrm{B}$ was proposed as the 3-amino-5-ethenyl-5-hydroxy-2-cyclopenten-1-one (5).

To substantiate our presumption and to establish the absolute stereochemistry of myrothenone B (5), the molecular structure with its absolute configuration of $N$ - $(p$-bromobenzoyl)myrothenone B $(\mathbf{5 a})^{14)}$ was determined by the X-ray crystal structure analysis (Fig. 1). ${ }^{15,16)}$
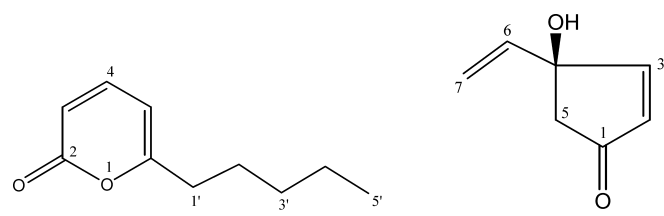

6-n-pentyl- $\alpha$-pyrone (1)

trichodenone A (2)

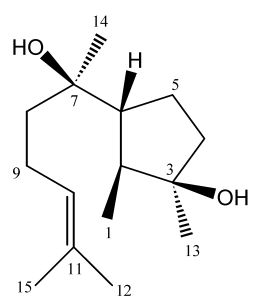

cyclonerodiol (3)

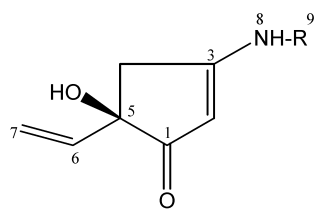

myrothenone $\mathrm{A}(\mathbf{4}): \mathrm{R}=\mathrm{CHO}$ myrothenone $\mathrm{B}(\mathbf{5}): \mathrm{R}=\mathrm{H}$ $p$-bromobenzoate (5a): $\mathrm{R}=\mathrm{COC}_{6} \mathrm{H}_{4} \mathrm{Br}$

* To whom correspondence should be addressed. e-mail: sonbw@pknu.ac.kr 
Table 1. NMR Data for Myrothenone A (4) and Myrothenone B (5)

\begin{tabular}{|c|c|c|c|c|}
\hline \multirow{2}{*}{$\mathrm{C} \#$} & \multicolumn{2}{|c|}{$4^{a)}$} & \multicolumn{2}{|c|}{$5^{b)}$} \\
\hline & $\delta_{\mathrm{H}}($ mult., $J$ ) & $\delta_{\mathrm{C}}$ (mult.) & $\delta_{\mathrm{H}}($ mult., $J$ ) & $\delta_{\mathrm{C}}$ (mult.) \\
\hline 1 & & $205.1(\mathrm{~s})$ & & $200.5(\mathrm{~s})$ \\
\hline 2 & $4.97(\mathrm{~s})$ & $98.2(\mathrm{~d})$ & $4.70(\mathrm{~s})$ & $95.8(\mathrm{~d})$ \\
\hline 3 & & $180.6(\mathrm{~s})$ & & $174.7(\mathrm{~s})$ \\
\hline \multirow[t]{2}{*}{4} & $2.64(\mathrm{~d}, 7.5)$ & $44.9(\mathrm{t})$ & $2.45(\mathrm{~d}, 17.1)$ & $42.7(\mathrm{t})$ \\
\hline & $2.86(\mathrm{~d}, 7.5)$ & & $2.61(\mathrm{~d}, 17.1)$ & \\
\hline 5 & & $80.6(\mathrm{~s})$ & & $78.1(\mathrm{~s})$ \\
\hline $5-\mathrm{OH}$ & & & $5.20(\mathrm{brs})$ & \\
\hline 6 & $5.83(\mathrm{dd}, 17.1,10.6)$ & $141.5(\mathrm{~d})$ & $5.76(\mathrm{dd}, 17.2,10.5)$ & $141.5(\mathrm{~d})$ \\
\hline \multirow[t]{2}{*}{7} & $5.18(\mathrm{dd}, 10.6,1.3)$ & $115.1(\mathrm{t})$ & $5.00(\mathrm{dd}, 10.5,1.7)$ & $112.3(\mathrm{t})$ \\
\hline & $5.41(\mathrm{dd}, 17.1,1.3)$ & & $5.20(\mathrm{dd}, 17.2,1.7)$ & \\
\hline \multirow[t]{2}{*}{8} & & & $7.30(\mathrm{brs})$ & \\
\hline & & & $7.56(\mathrm{brs})$ & \\
\hline 9 & $8.11(\mathrm{~s})$ & $164.1(\mathrm{~d})$ & & \\
\hline
\end{tabular}

a) Recorded in $\mathrm{CD}_{3} \mathrm{OD}$ at $400 \mathrm{MHz}\left({ }^{1} \mathrm{H}\right)$ and $100 \mathrm{MHz}\left({ }^{13} \mathrm{C}\right)$ at $-50{ }^{\circ} \mathrm{C}$. b) Recorded in DMSO- $d_{6}$ at $400 \mathrm{MHz}\left({ }^{1} \mathrm{H}\right)$ and $100 \mathrm{MHz}\left({ }^{13} \mathrm{C}\right)$.

Bond distances and angles were all normal. The C-1, C-2, $\mathrm{C}-3$, and $\mathrm{C}-4$ atoms were in a plane with the maximum deviation of $0.004 \AA$, and C-5 is displaced toward beta-orientation from the plane of the other four [diagonal angle: 15.1 $(0.5)]$. Therefore, the cyclopentenone of $\mathbf{5}$ shows a typical envelope geometry.

The absolute configuration of asymmetric center for $\mathbf{5}$ has been unambiguously determined to be $5 R$ by refinement of the Flack parameter. ${ }^{17}$

Myrothenone A (4), ${ }^{18)}$ which is a formamide derivative of 5, was obtained as a very unstable colorless oil, and the HRFAB-MS and ${ }^{13} \mathrm{C}$-NMR methods established the molecular formula to be $\mathrm{C}_{8} \mathrm{H}_{9} \mathrm{NO}_{3}$. The general features of its UV, IR and NMR spectra (Table 1) closely resembled those of myrothenone $\mathrm{B}(5)$, except that additional NMR signals of a new formamide $\left[\delta_{\mathrm{H}} 8.11(\mathrm{H}-9), \delta_{\mathrm{C}} 164.1\right.$ (C-9)] appeared (Table 1). ${ }^{19)}$ The NMR signals of 4 measured at r.t. were deformed because of its instability. So, all the NMR data were obtained at a low temperature $\left(-50^{\circ} \mathrm{C}\right)$.

Detailed analyses of the ${ }^{1} \mathrm{H}$ - and ${ }^{13} \mathrm{C}-\mathrm{NMR}$ spectra of 4 , including the results from DEPT, HMQC, and HMBC experiments, suggested the metabolite (4) is a formamide derivative of 5. The key HMBC correlation from H-9 to C-3 was critical in establishing the location of aldehyde of 4 as shown.

On the basis of these data, the structure of myrothenone A was proposed as the 5-ethenyl-3-formamido-5-hydroxy-2-cyclopenten-1-one (4). In order to clarify the structure of 4 , we synthesized 4 from myrothenone B (5) and formic acid using 1,3-dicyclohexylcarbodiimide (DCC) as a base. ${ }^{20,21)}$ The spectral data of synthetic compound were identical to those of myrothene B (5) in all aspects. Accordingly, the absolute stereostructure of myrothenone A was determined as $5(R)-5$ ethenyl-3-formamido-5-hydroxy-2-cyclopenten-1-one (4).

Vinylcyclopentenone analogues have been reported as the artifact ${ }^{22)}$ and the conjugated adduct, ${ }^{23)}$ but natural products of this class having amino group $(4,5)$ are very rare example.

6- $n$-Pentyl- $\alpha$-pyrone (1) and myrothenone A (4) exhibited a tyrosinase inhibitory activity with $\mathrm{ED}_{50}$ value of 0.8 and $6.6 \mu \mathrm{M}$, respectively, which are more active than kojic acid $\left(\mathrm{ED}_{50}, 7.7 \mu \mathrm{M}\right)$ currently being used as a functional personal-

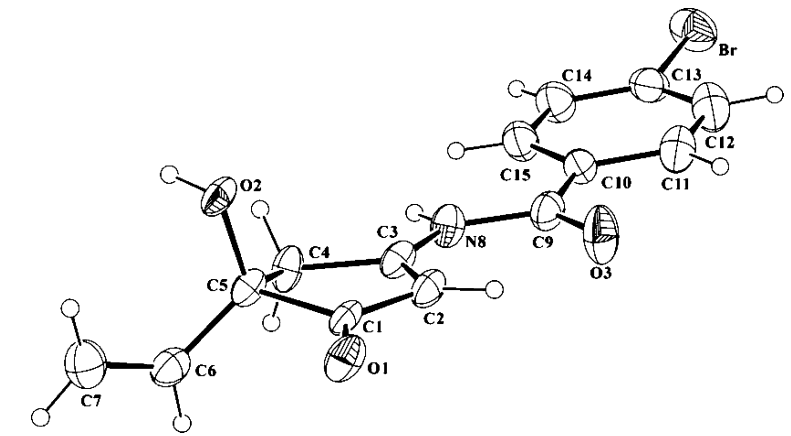

Fig. 1. An ORTEP III ${ }^{16)}$ Drawing of $p$-Bromobenzoate (5a)

Displacement ellipsoids are drawn at $30 \%$ probability level.

care compound.

The further biological evaluation of $\mathbf{1}, \mathbf{2}, \mathbf{3}, \mathbf{4}$, and $\mathbf{5}$ is in progress.

Acknowledgements X.L. acknowledges the support of the Brain Korea 21 (BK21) (F020). Circular dichroism (CD) and Mass spectral data were kindly provided by the Korea Basic Science Institute. This work was supported by MarineBio21 (Ministry of Maritime Affairs and Fisheries, Korea).

\section{References and Notes}

1) Faulkner D. J., Nat. Prod. Rep., 19, 1-47 (2002).

2) Pietra F., Nat. Prod. Rep., 14, $453-464$ (1997).

3) Andersen R. J., Williams D. E., "Chemistry in the Marine Environment," ed. by Hester R. E., Harrison R. M., The Royal Society of Chemistry, Cambridge, 2000, pp. 55-79.

4) Shin N. H., Lee K. S., Kang S. H., Min K. R., Lee S. H., Kim Y., Nat. Prod. Sci., 3, 111-121 (1997) and references cited therein. [Iwata M., Corn T., Iwata S., Everett M. A., Fuller B. B., J. Invest. Dermatol., 95, $9-15$ (1990)].

5) Li X., Li Y., Jeong J. H., Lee K. T., Choi H. D., Son B. W., Kor. J. Pharmacogn., 34, 138-141 (2003).

6) Li X., Jeong J. H., Lee K. T., Rho J. R., Choi H. D., Kang J. S., Son B. W., Arch. Pharm. Res., 26, 532-534 (2003).

7) Simon A., Dunlop R. W., Ghisalberti E. L., Sivasithamparam K., Soil Biol. Biochem., 20, 263-264 (1988).

8) Usami Y., Numata A., Synlett., 1999, 723-724 (1999).

9) Li X., Kim S.-K., Kang J. S., Choi H. D., Son B. W., Bull. Korean Chem. Soc., 25, 607-608 (2004).

10) The fungal strain was identified as an Myrothecium sp. based on fatty acid methyl ester analysis (Korean Culture Center of Microorganisms, Seoul, Korea), similarity index 0.697. 
11) The fungus was cultured for $30 \mathrm{~d}$ (static) at $29^{\circ} \mathrm{C}$ in SWS medium: soytone $(0.1 \%)$, soluble starch $(1.0 \%)$, and seawater $(100 \%)$.

12) Myrothenone $B(5)$ was isolated as a colorless oil which showed: $[\alpha]_{\mathrm{D}}^{20}=+35^{\circ}(c=0.6, \mathrm{MeOH}) ; \mathrm{IR}(\mathrm{KBr}) 3390,3210,1630,1552$, $1414,1271,1221,1123,1072 \mathrm{~cm}^{-1}$; UV (MeOH) $203 \mathrm{~nm}(\log \varepsilon 3.7)$ 268 (4.0); LR-EI-MS m/z 139 [M] $^{+}$(rel. int. 87), $122[\mathrm{M}-\mathrm{OH}]^{+}$(13), 110 (84), 94 (33), 83 (83), 67 (32), 55 (100); HR-FAB-MS m/z $140.0710[\mathrm{M}+\mathrm{H}]^{+}\left(\right.$Calcd for $\left.\mathrm{C}_{7} \mathrm{H}_{10} \mathrm{NO}_{2}, 140.0712\right)$; see Table 1 for NMR spectral data.

13) ${ }^{13}$ C-NMR Spectroscopy of Organic Compounds; "Carbon-13 NMR Spectroscopy," ed. by Breitmaier E., Voelter W., VCH, Weinheim, Germany, 1990, pp. 238-240.

14) $p$-Bromobenzoyl chloride $(0.3 \mathrm{ml})(0.2 \mathrm{mmol})$ was added to a solution of myrothenone B (5) $(20 \mathrm{mg})(0.5 \mathrm{mmol})$ in pyridine at $0{ }^{\circ} \mathrm{C}$ under $\mathrm{N}_{2}$ atmosphere, then the mixture was stirred for $12 \mathrm{~h}$ at $60^{\circ} \mathrm{C}$. The reaction mixture was then poured into water and extracted with EtOAc. The EtOAc extract was washed with brine, then dried over $\mathrm{MgSO}_{4}$. Removal of the solvent under reduced pressure from the EtOAc extract gave a product, which was purified by column chromatography ( $n$ hexane-EtOAc $=20: 1)$ to furnish $p$-bromobenzoate derivative (5a, $18 \mathrm{mg}$ ) (Fig. 1).

15) The Crystallographic data were, $\mathrm{C}_{14} \mathrm{H}_{12} \mathrm{BrNO}_{3}, \quad \mathrm{MW}=322.16$, $T=298(2) \mathrm{K}, \lambda=0.71069 \AA$, monoclinic, $P 2_{1}, \quad a=5.6300(10), \quad b=$ 5.685(3), $\quad c=20.715(3) \AA, \quad \beta=94.850(10)^{\circ}, \quad V=660.6(2) \AA^{3}, \quad Z=2$, $d_{\text {calcd. }}=1.619 \mathrm{Mg} \mathrm{m}^{-3}, F(000)=324$, The final $R_{1}$ and $w R_{2}$ values with 3375 Friedel pair reflections $([I>2 \sigma(I)])$ were 0.0502 and 0.0541 , respectively. An absolute structure parameter, $\chi=-0.02(1) .{ }^{17)}$ Crystallographic data have been deposited with the Cambridge Crystallographic
Data Center (deposit No. CCDC 256884).

16) Farrugia L. J., J. Appl. Cryst., 30, 565-566 (1997).

17) Flack H. D., Acta Crystallogr., A39, 876-881 (1983).

18) Myrothenone A (4) was isolated as a colorless oil which showed: $[\alpha]_{\mathrm{D}}^{20}=+61^{\circ}(c=0.6, \mathrm{MeOH})$; IR $(\mathrm{KBr}) 3419,3240,1683,1603$, 1554, 1524, 1410, 1318, 1189, 1093, $1005 \mathrm{~cm}^{-1}$; UV (MeOH) $203 \mathrm{~nm}$ ( $\log \varepsilon$ 3.7), 272 (4.2); LR-EI-MS $m / z 167[\mathrm{M}]^{+}$(rel. int. 34), 139 $[\mathrm{M}-\mathrm{CO}]^{+}(50), 122[\mathrm{M}-\mathrm{CO}-\mathrm{OH}]^{+}(10), 111(43), 94(54), 84$ (43), 68 (72), 55 (100); HR-FAB-MS $m / z 190.0482[\mathrm{M}+\mathrm{Na}]^{+}$(Calcd for $\left.\mathrm{C}_{8} \mathrm{H}_{9} \mathrm{NO}_{3} \mathrm{Na}, 190.0480\right)$; see Table 1 for NMR spectral data.

19) "Structure Determination of Organic Compounds, Tables of Spectral Data," ed. by Pretsch E., Buhlmann P., Affolter C., Springer, Berlin, 2000 , p. 140 and 224.

20) Waki M., Meienhofer J., J. Org. Chem., 42, 2019-2020 (1977).

21) Formic acid $(0.5 \mathrm{ml})(12.7 \mathrm{mmol})$ and DCC $(5 \mathrm{mg})$ was added to a solution of myrothenone B (5) $(10 \mathrm{mg})(0.5 \mathrm{mmol})$ in pyridine at $0{ }^{\circ} \mathrm{C}$ under $\mathrm{N}_{2}$ atmosphere, then the mixture was stirred for $3 \mathrm{~h}$. The reaction mixture was then poured into water and extracted with EtOAc. The EtOAc extract was washed with brine, then dried over $\mathrm{MgSO}_{4}$. Removal of the solvent under reduced pressure from the EtOAc extract gave a product, which was purified by column chromatography ( $n$ hexane-EtOAc $=20: 1)$ to furnish myrothenone A $(8 \mathrm{mg})$. Synthetic compound was shown to be identical with myrothenone A (4) by TLC, $[\alpha]_{\mathrm{D}},{ }^{1} \mathrm{H}-$ and ${ }^{13} \mathrm{C}-\mathrm{NMR}$.

22) Mukhopadhyay T., Roy K., Sawant S. N., Deshmukh S. K., Ganguli B. N., Fehlhaber H. W., J. Antibiot., 49, 210-211 (1996).

23) Parshikov I. A., Moody J. D., Freeman J. P., Jr., Lay J. O., Williams A. J., Heinze T. M., Sutherland J. B., Mycologia, 94, 1—5 (2002). 